RIVERA R, Edison Leandro. Descripción legislativa preliminar del arbitraje nacional e internacional en Brasil y Colombia. Revista Eletrônica Direito e Política, Programa de Pós-Graduação Stricto Sensu em Ciência Jurídica da UNIVALI, Itajaí, v.13, n.1, $1^{0}$ quadrimestre de 2018. Disponível em: www.univali.br/direitoepolitica - ISSN 1980-7791

\title{
DESCRIPCIÓN LEGISLATIVA PRELIMINAR DEL ARBITRAJE NACIONAL E INTERNACIONAL EN BRASIL Y COLOMBIA
}

\author{
PRELIMINARY LEGISLATIVE DESCRIPTION OF NATIONAL AND INTERNATIONAL \\ ARBITRATION IN BRAZIL AND COLOMBIA
}

Edison Leandro Rivera Rueda ${ }^{1}$

Sumario: Introducción; 1 Contexto legal de los mecanismos alternativos de solución de conflictos (MASC) en Colombia y Brasil; 2 El arbitraje como fuente de obligaciones en Brasil y Colombia, surgidas en justicia particular; 3 El arbitraje internacional: retos y avances en Brasil y Colombia; Consideraciones finales; Referencia de las fuentes citadas.

\section{RESUMEN}

La aplicación de mecanismos de solución de conflictos, distintos a los convencionales, es un tema que ha tomado relevancia en el mundo jurídico y comercial. El arbitraje es una de sus formas y se abre paso, no solamente como herramienta de descongestión judicial, sino de solución efectiva de litigios, a partir de justicia consensuada. El presente artículo se propone mostrar al lector una revisión preliminar de contextos, autores y normas relevantes para la evolución de este mecanismo. El análisis se centrará en la estructuración de los principios, normas generales del arbitraje y su aplicación en dos ordenamientos particulares (Brasil y Colombia) y el avance de estos a la fecha.

Palabras clave: Arbitraje; Brasil; Colombia; Derecho Comparado.

\section{ABSTRACT}

The application of conflict resolution mechanisms, different from the conventional ones, is an issue that has taken relevance in the legal and commercial world. Arbitration is one of its forms and it opens the way, not only as a judicial decongestion tool, but also as an effective solution to litigation, based on consensual justice. This article aims to show the reader a preliminary review of relevant contexts, authors and norms for the evolution of this mechanism. The analysis will focus on the structuring of the principles, general rules of arbitration and their application in two systems (Brazil and Colombia) and their progress to date.

Key words: Arbitration; Brazil; Colombia; Comparative Law.

\footnotetext{
${ }^{1}$ Abogado, especialista en derecho administrativo y constitucional, candidato a Magister en derecho público y a Mestre em Ciência jurídica. Contacto: Carrera 3 No. 13-20 Oficina 303, Ibagué - Tolima, Colombia. Tel. +57Cel. 3183083375 - androwlive@gmail.com
} 
RIVERA R, Edison Leandro. Descripción legislativa preliminar del arbitraje nacional e internacional en Brasil y Colombia. Revista Eletrônica Direito e Política, Programa de Pós-Graduação Stricto Sensu em Ciência Jurídica da UNIVALI, Itajaí, v.13, n.1, $1^{0}$ quadrimestre de 2018. Disponível em: www.univali.br/direitoepolitica - ISSN 1980-7791

\section{INTRODUCCIÓN}

El presente artículo tiene como objetivo describir los avances normativos que, sobre mecanismos alternativos de solución de conflictos y en especial el arbitraje, han tenido los ordenamientos de Brasil y Colombia. Se examinarán los antecedentes normativos, algunas expresiones jurisprudenciales y posiciones doctrinales que apoyarán la hipótesis de que existen grandes similitudes entre los sistemas, con leves diferencias que, en todo caso, pudieron marcar el avance del uno y el retraso del otro.

La importancia de esta preliminar investigación tiene dos ejes: jurídico y social. Desde los jurídico será importante, pues representa un interesante esfuerzo por analizar legislación comparada. La comparación de ordenamientos siempre será un punto destacado en investigaciones jurídicas, pues permite evidenciar fortalezas y debilidades de cada uno o qué tienen en común, sirviendo de ayuda a quienes tienen intereses en ordenamientos extranjeros. Desde lo social, el trabajo puede representar un diagnóstico de situaciones ajenas a las normas, que pueden tener resultados favorables o desfavorables en una sociedad e incidir en la eficacia de su sistema jurídico.

Para lograr el objetivo planteado, se parte de exponer brevemente el contexto de los mecanismos alternativos de solución de conflictos en ambos estados. La descripción es netamente pedagógica y no integra tantos aspectos interdisciplinarios que podría tener, aunque solamente se hace con fines ilustrativos, para poder centrar la discusión en el punto álgido del artículo: el arbitraje. Frente a éste, el artículo se propone dividirlo en dos clases: nacional e internacional.

En el desarrollo del texto se expondrá la forma en que la década del noventa (90) fue relevante para ambas vertientes del arbitraje en los dos países. En ambos casos se planteará relevancia que han tenido los principios internacionales del arbitraje, más allá de los propios del procedimiento y la prueba judicial. Igualmente, se hará referencia a la relevancia que obtienen normas internacionales como la convención de Nueva York y las normas interamericanas de comercio, así como las regulaciones del UNICITRAL. 
RIVERA R, Edison Leandro. Descripción legislativa preliminar del arbitraje nacional e internacional en Brasil y Colombia. Revista Eletrônica Direito e Política, Programa de Pós-Graduação Stricto Sensu em Ciência Jurídica da UNIVALI, Itajaí, v.13, n.1, $1^{0}$ quadrimestre de 2018. Disponível em: www.univali.br/direitoepolitica - ISSN 1980-7791

Para Brasil, se hará un parangón entre el antes y después de la Ley 9307 de 1996, modificada por la ley 13.129 de 2015 y el avance que ésta ha permitido. Para Colombia, se expondrán los avances logrados, a partir de la Ley 315 de 1996, el decreto 1818 de 1998 y la ley 446 de 1998, que instruyeron el tema por varios años hasta la emisión de la Ley 1563 de 2012, que es la norma más completa y reciente sobre el tema.

El análisis comprenderá estudios sobre el procedimiento y sobre la ley sustancial aplicable. Finalmente, se hará un breve análisis sobre las ventajas y retos que tendría el arbitraje internacional en ambos países, comparando algunos resultados y las posibles opciones a seguir, las cuales se presentarán a manera de conclusión o reflexión final.

El tipo de investigación es de corte cualitativa con enfoque hermenéutico, donde la finalidad tiene dos ejes: la comprensión y la interpretación, con más relevancia en este último. En principio será necesaria la interpretación de fenómenos históricos, políticos y normativos para luego comprender el contexto de éstos, haciendo hincapié en la necesaria vinculación de análisis propios de las ciencias sociales dándole enfoque estructuralista, aunque con algunos matices positivistas. Esto en razón a que, si bien los métodos científicos no determinan la validez de ciencias sociales, sí sirven de herramientas para indagar una cultura o un texto (Herrera González, 2012).

\section{CONTEXTO LEGAL DE LOS MECANISMOS ALTERNATIVOS DE SOLUCIÓN DE CONFLICTOS (MASC) EN COLOMBIA Y BRASIL}

Los mecanismos alternativos de solución de conflictos han tomado un espacio relevante en el contexto jurídico global, vinculados desde el mismo origen de las civilizaciones en escenarios morales, acordados y sin coacción ${ }^{2}$. Mecanismos como la mediación y hasta la misma conciliación no son ajenos a los ordenamientos jurídicos globales en su historia, sin embargo, solamente hasta los años setentas (70's) puede hablarse de una vinculación directa de éstos como "alternatives"

${ }^{2}$ Folberg, J., \& Taylor, A. Mediación: resolución de conflictos sin litigio. México D.F.: Editorial Limusa S.A. de C.V. 1996. p. 27 
RIVERA R, Edison Leandro. Descripción legislativa preliminar del arbitraje nacional e internacional en Brasil y Colombia. Revista Eletrônica Direito e Política, Programa de Pós-Graduação Stricto Sensu em Ciência Jurídica da UNIVALI, Itajaí, v.13, n.1, $1^{0}$ quadrimestre de 2018. Disponível em: www.univali.br/direitoepolitica - ISSN 1980-7791

respecto del litigio ${ }^{3}$. Latinoamérica no es la excepción y en esto Argentina ha sido pionero con más de veinte (20) años de experiencia 4 . Brasil y Colombia han respondido positivamente a este movimiento jurídico, con importantes cambios en sus ordenamientos.

Si bien, en Colombia puede hablarse de mecanismos alternativos desde el año 1948 cuando el código de procedimiento laboral, en su capítulo IV, menciona la conciliación como herramienta para terminar conflictos de este tipo, lo cierto es que este avance fue incipiente para la época. El desarrollo normativo también se remonta a la adopción del llamado juicio arbitral, ya hace más de un siglo, por medio de la Ley 105 de 1890, sumado a las regulaciones y reformas de la Ley 103 de 1923, 105 de 1931, la ley 2a de 1938 y los demás códigos de procedimiento civil y comerciales del período 5 .

El punto crucial de los mecanismos alternativos de solución de conflictos en Colombia fue la expedición de la constitución política de 1991, la cual, en su artículo 116, invistió de facultades provisionales a particulares, para excepcionalmente administrar justicia. Con esta disposición constitucional se dio avance a los mecanismos que se fueron regulando en normas como la Ley 640 de 2001, 1563 de 2012, Decreto 1818 de 1998, Decreto 1069 de 2015, entre otros. Normas que han definido un marco para la Conciliación, la mediación, la amigable comisión, el arbitraje y la transacción, esta última a partir del mismo código civil, que la considera un contrato a la luz de las previsiones del artículo 2469 y ss.

En Brasil, el análisis del conflicto ha sido punto de partida para el examen de los litigios y su posible solución ${ }^{6}$, visión que es compartida por la mayoría de los

\footnotetext{
3 Palandri, E. Manual de formación básica en mediación. Córdoba, Argentina: Ediciones Alveroni, 2015, p. 49

4 Álvarez, G. S. Mapa regional de resolución aternativa de disputas. 05 de agosto de 2017. Buenos Aires, Argentina. Recuperado el 23 de noviembre de 2017 de http://www.maparegional.gob.ar/accesoJusticia /documents/verDocumento.html?idDocumento=1

5 Salcedo Flórez, Á. La autonomía de las partes en el arbitraje ad hoc frente al orden público procesal (Primera ed.). Bogotá D.C. Universidad de Bogotá Jorge Tadeo Lozano. 2012. p. 18

6 Fernandes Marques, A., Teixeira, L. X., \& Amaral, N. mecanismos alternativos de solução de conflitos: conciliação, mediação e arbitragem. pp. 32-48. Ponto de Vista Jurídico. Caçador, S.C. enero-junio de 2013. Disponível em: http://periodicos.uniarp.edu.br/juridico/article/view/82/164 Acesso em 04/05/2018
} 
RIVERA R, Edison Leandro. Descripción legislativa preliminar del arbitraje nacional e internacional en Brasil y Colombia. Revista Eletrônica Direito e Política, Programa de Pós-Graduação Stricto Sensu em Ciência Jurídica da UNIVALI, Itajaí, v.13, n.1, $1^{\circ}$ quadrimestre de 2018. Disponível em: www.univali.br/direitoepolitica - ISSN 1980-7791

estados en que se aplican estos mecanismos. Pese a ello, la historia no fue muy amable con este propósito, en tanto la dictadura militar, comenzada en 1964 y finalizada en 1985, impidió el conocimiento de muchos casos a la jurisdicción. Para finales de la década de los setentas (70's), inició en el país el movimiento denominado "segunda onda renovatoria", la cual llevó al conocimiento de la rama judicial muchos aspectos que antes no eran de su competencia. Situación que se incrementó con la expedición de la constitución de 1988, generando una especie de garantía para los ciudadanos que no podían ver garantizados los derechos del estado social de derecho? ${ }^{7}$.

Pese a lo anterior, este movimiento generó una gran congestión judicial, requiriendo una tercera "onda renovatoria", que diera respuesta a la problemática y utilizara métodos no judiciales de composición de $\operatorname{conflictos}^{8}$. El derogado código de proceso civil, Ley N.o 5.869 de 1973, ya preveía la posibilidad de acudir a mecanismos como la conciliación para resolver conflictos, ya sea de forma judicial o extrajudicial, situaciones ratificadas en las reformas del año 1996, 1998 y 2002. El nuevo código de proceso brasilero, Ley 13.105 de 2015, desarrolla con más fluidez estos mecanismos y su connotación internacional, le otorga importantes cualidades al arbitraje internacional, especialmente desde sus principios globales, tal como se predica en los artículos $21,22,23$ y ss 9 .

Igualmente, vale la pena la mención de la "política judiciária nacional de tratamento dos conflictos de interesses", consignada en la resolución No. 125 de 2010, expedida por el Conselho Nacional de Justicia. Política que busca la aplicación de medios adecuados a la naturaleza e peculiaridad de cada asunto.

Estas iniciativas han servido para darle fuerza a agremiaciones de este tipo, tales como el instituto de mediación y arbitraje en Brasil (IMAB). La mediación es uno de los mecanismos que, si bien no tiene fuerza coercitiva, ha permitido solucionar

\footnotetext{
7 Lopes, J. R. Direitos sociais: teoría e prática. São Paulo: Método. 2006. p. 109

8 Cappeletti, M., \& Garth, B. El acceso a la justicia: la tendencia en el movimiento mundial para hacer efectivos los Derechos. México D.F.: Fondo de Cultura Económica. 1996. p. 39

${ }^{9}$ Borges Motta, F. J., \& Tomaz de Olivera, R. Livro II Da função jurisdiccional - Título I Da jurisdição e da ação. En L. L. Streck, D. Nunes, \& L. Carneiro da cunha, Comentários ao Código de proceso civil (págs. 64-87). São Paulo: Editoria Saraiva. 2016. p. 70-71
} 
RIVERA R, Edison Leandro. Descripción legislativa preliminar del arbitraje nacional e internacional en Brasil y Colombia. Revista Eletrônica Direito e Política, Programa de Pós-Graduação Stricto Sensu em Ciência Jurídica da UNIVALI, Itajaí, v.13, n.1, $1^{\circ}$ quadrimestre de 2018. Disponível em: www.univali.br/direitoepolitica - ISSN 1980-7791

muchos problemas jurídico-sociales. El arbitraje representa también un avance considerable desde la aparición de la Ley 9307 de 1996, permitiendo la aplicación temporal de justicia por parte de particulares. De ahí que la norma en mención permita (artículo 2) en tres órdenes arbitrales a saber: derecho, equidad y convencional, éste último entendido de acuerdo con la voluntad de las partes.

Particularmente, para esta presentación, reviste importancia el avance que este mecanismo de solución de conflictos ha tenido y sus consecuencias en el ámbito local e internacional. De ahí que las relaciones que el arbitraje tiene, directa o indirectamente, con las normas internacionales será un punto importante de estudio y se planteará, de acuerdo con la adopción o no de las convenciones y tratados que éstas compongan.

\section{EL ARBITRAJE COMO FUENTE DE OBLIGACIONES EN BRASIL Y COLOMBIA, SURGIDAS EN JUSTICIA PARTICULAR}

En Brasil, el arbitraje tiene una relevancia histórica a partir de la Ley 9307 de 1996 o también llamada Ley de Arbitraje (LA). No obstante, los orígenes de este mecanismo se remontan a la misma expedición de la constitución del imperio de 1824, particularmente en el artículo 160. La evolución indica que se expidieron regulaciones en seguros, tales como Resolución del 26 de julio de 1831 y la Ley 108 del 11 de octubre de 1837. Ello sin hacer mención al código de comercio de 1850, la constitución federal de 1895 y la de $1937^{10}$.

Sin embargo, el gran antecedente de la estructura jurídica del arbitraje actual en Brasil corresponde a la Constitución de 1988 y la adopción de tratados y convenios internacionales. En la constitución se destaca, desde el mismo preámbulo, el respeto a la justicia dictada por jueces y particulares. Situación que permitió la emisión de la Ley 9307 de 1996.

La LA tiene, como más destacados principios, los de la autonomía de la voluntad, buena fe, imparcialidad, libre convencimiento del árbitro, igualdad de las partes y

\footnotetext{
10 De Souza Tavares, V. Arbitragem no Brasil. Âmbito Jurídico, XVII(121). Río Grande R.S. febrero de 2014. Disponible en http://www.ambitojuridico.com.br/site/?n_link=revista_artigos_leitura\&artigo_id=14424 Último acceso el 26 de enero de 2018
} 
RIVERA R, Edison Leandro. Descripción legislativa preliminar del arbitraje nacional e internacional en Brasil y Colombia. Revista Eletrônica Direito e Política, Programa de Pós-Graduação Stricto Sensu em Ciência Jurídica da UNIVALI, Itajaí, v.13, n.1, $1^{0}$ quadrimestre de 2018. Disponível em: www.univali.br/direitoepolitica - ISSN 1980-7791

la autonomía de la cláusula compromisoria, entre otros. Los principios que tienen que ver con el procedimiento y práctica de la prueba tienen fuente directa en los principios probatorios, situación por la cual no se hará mayor alusión. No obstante, existen principios que sí fueron integrados por vía del desarrollo de este mecanismo, particularmente desde su fuente internacional.

Así, la autonomía de la cláusula compromisoria es uno de los principios más destacados en el horizonte internacional. Por este principio, se reconoce al pacto arbitral como una categoría contractual independiente del contrato en el que está adoptado $^{11}$. Es de suma importancia su reconocimiento, por parte de la LA, pues antes de ello las partes llegaban a alegar la nulidad del contrato primigenio y con ello impedían la continuación del arbitraje. El simple argumento de la nulidad permitía a la jurisdicción ordinaria conocer el trámite, cosa que se convertía en un obstáculo para el desarrollo del arbitramento local en Brasil, amén que se constituía en estrategia dilatoria. Hoy en día, con la LA, esta fase se ha superado y es el árbitro quien resuelve ambas peticiones, tanto la nulidad del contrato primigenio, como de la inherente al pacto arbitral ${ }^{12}$ (Mitsuo Miura \& Nasser Vidal, 2016, págs. 324-325).

Otro gran principio del arbitramento, cuya fuente principal deviene del desarrollo internacional, es el denominado "Kompetenz-Kompetenz". Dicho principio hace referencia a la atribución, por parte del tribunal arbitral, para decidir sobre su propia competencia. La misma LA permite ver a este principio en dos dimensiones a saber: una positiva y una negativa. La positiva ratifica la facultad de decidir sobre la propia competencia. La negativa reconoce dos competencias simultáneas a saber: la del tribunal arbitral y la de la jurisdicción ordinaria. Ambas para decidir cuestiones relativas a la validez, eficacia y aplicabilidad del pacto arbitral ${ }^{13}$. El

\footnotetext{
11 Lew, J., Mistelis, L., \& Kröll, S. The Hague: Comparative International Commercial Arbitration. Alphen aan den Rijn, Holanda: Kluwer Law International. 2003. p.102

12 Mitsuo Miura, A., \& Nasser Vidal, R. C. A relativização do principio Kómpetenz - Kómpetenz pelo STJ: Um breve comentário ao julgamento do recurso especial 1.602.076/SP. Revista Jurídica da Escola Superior de Advocacia da OAB-PR, año 1(2), 316-339. año 1(2). Curitiba - Paraná. Disponible en http://revistajuridica.esa.oabpr.org.br/wp-content/uploads/2016/12/2-0-revistajuridica.pdf Último acceso el 31 de enero de 2018. p. 324-325

13 Lew, J., Mistelis, L., \& Kröll, S. The Hague: Comparative International Commercial Arbitration. p.330
} 
RIVERA R, Edison Leandro. Descripción legislativa preliminar del arbitraje nacional e internacional en Brasil y Colombia. Revista Eletrônica Direito e Política, Programa de Pós-Graduação Stricto Sensu em Ciência Jurídica da UNIVALI, Itajaí, v.13, n.1, $1^{\circ}$ quadrimestre de 2018. Disponível em: www.univali.br/direitoepolitica - ISSN 1980-7791

artículo 20 de la LA claramente facultaba a los tribunales arbitrales para decidir, en principio sobre estos aspectos, al tiempo que permitiría, en un futuro, juzgarlos por parte de los jueces.

La jurisprudencia brasilera, en un principio, fue reacia a esta competencia, favoreciendo a quien alegaba estos aspectos en procura de obtener el conocimiento de la justicia ordinaria. Se afirmaba que acudir al arbitraje "não se trata de impedir o acesso ao judiciário"14, con lo que parecía favorecerse la postura de una exclusiva intervención judicial inmediata en algunos de estos aspectos. No obstante, posteriormente se aceptó la intervención inicial del árbitro sobre estos aspectos, pudiendo el juez revisarlo en momentos posteriores. Situaciones que llevaron a relativizar el debate, especialmente por la variedad de tribunales judiciales con los que cuenta Brasil. La mayoría de los casos va dirigida al respeto de la competencia del tribunal arbitral hasta el final, sin embargo, recientemente una decisión del STJ, parecería permitir la intervención del juez ante evidentes nulidades e ilegalidades de la cláusula compromisoria, de tal manera que la relatividad puede continuar ${ }^{15}$.

Finalmente, otro de los principios arbitrales -más allá de los procesalescorresponde a la denominada "acessibilidade ao judiciário". Principio que haría referencia a la posibilidad de acudir a la justicia ordinaria, para demandar en nulidad a los laudos arbitrales. Este verdaderamente se relaciona con los principios procesales, especialmente los asegurados en la ley, tales como el contradictorio del proceso, las propios de la prueba judicial y la autonomía de la voluntad ${ }^{16}$.

Las formas de acudir a la justicia arbitral en Brasil son dos: a través de una cláusula compromisoria y a través de un compromiso arbitral. La cláusula compromisoria es la figura propia del principio de la autonomía de la cláusula, que, como ya se

14 Tribunal de Justiça do Distrito Federal e Territórios - 3ra Turma civil. Apelação cível n.º 1999.01.1.083360-3, Desembargador Vasquez Cruxên, partes Americel S/A vs Compushopping informática Itda ME e outros. 2001 de marzo de 2001.

15 Lew, J., Mistelis, L., \& Kröll, S. The Hague: Comparative International Commercial Arbitration. p.335, 336, 337.

16 Lemes , S. F. Aspectos fundamentais da Lei de Arbitragem. Rio de Janeiro: Forense. 1999. p. 73. 
RIVERA R, Edison Leandro. Descripción legislativa preliminar del arbitraje nacional e internacional en Brasil y Colombia. Revista Eletrônica Direito e Política, Programa de Pós-Graduação Stricto Sensu em Ciência Jurídica da UNIVALI, Itajaí, v.13, n.1, $1^{0}$ quadrimestre de 2018. Disponível em: www.univali.br/direitoepolitica - ISSN 1980-7791

dijo, convierte a esta estipulación en un contrato principal, el cual no depende del contrato primigenio.

Ahora bien, los artículos 7, 8 y 9 de la LA prevén el denominado compromiso arbitral. Dicho compromiso tiene dos vertientes a saber: la creación y la supresión del procedimiento arbitral. La supresión tiene que ver con la posibilidad radicada en las partes para, aun teniendo cláusula compromisoria, acudir a la justicia ordinaria, acabando con el juicio arbitral. La creación es completamente lo contrario, ya que permite a las partes de un proceso judicial la suscripción de un compromiso que permita llevar las diferencias a un tribunal de arbitramento. El artículo 9 de la LA define el primero como arbitraje judicial y al segundo como arbitraje extrajudicial, requiriendo el uso de memoriales y registro en el proceso para el judicial, así como una escritura privada, firmada por dos testigos ante notario.

Por otra parte, es importante destacar que, una vez expedida la LA, hubo importantes pronunciamientos sobre la aplicación del trámite arbitral. Temas como los contratos de adhesión y relaciones de consumo, arbitraje de entidades públicas sobre derechos patrimoniales disponibles, aplicación del principio de publicidad, la anulación de los laudos arbitrales parciales, prórroga del procedimiento, el nombramiento de árbitros, el arbitraje societario, entre otros, fueron temas que debieron ser esclarecidos por regulaciones posteriores 0 por la misma jurisprudencia ${ }^{17}$.

Frente a las relaciones de consumo, existió un importante choque de trenes respecto del llamado "código de defensa del consumidor" (CDC), toda vez que éste último prevé un procedimiento especial para este tipo de controversias. El Superior Tribunal de Justicia debió aclarar esta situación, indicando que, si bien existe este procedimiento especial, ello no obsta para que los consumidores puedan optar por el arbitraje, sin que ello sea una regla aun previéndose una convención que así lo

\footnotetext{
17 Lemes, S. M. Anotações sobre a nova Lei de arbitragem. Revista de arbitragem e mediação, XVII, 37-44. São Paulo. Octubre - diciembre de 2015. p. 38.
} 
RIVERA R, Edison Leandro. Descripción legislativa preliminar del arbitraje nacional e internacional en Brasil y Colombia. Revista Eletrônica Direito e Política, Programa de Pós-Graduação Stricto Sensu em Ciência Jurídica da UNIVALI, Itajaí, v.13, n.1, $1^{0}$ quadrimestre de 2018. Disponível em: www.univali.br/direitoepolitica - ISSN 1980-7791

diga en el contrato ${ }^{18}$. A ello se le sumó que el nuevo código de procedimiento civil del año 2015, en armonía con lo previsto en la nueva ley de mediación, permiten acudir a mecanismos alternativos de solución de conflictos, inclusive sin cláusula compromisoria, sino con un simple requerimiento a la parte.

En cuanto al arbitraje de entidades públicas, solamente el que corresponde a sociedades de economía mixta fue de relevancia histórica, el cual encuentra oposición antes de la LA. Providencias como la REsp 612439 RS 2003/0212460-3 y la MS 11308 DF 2005/0212763-0 del Superior Tribunal de Justiça (STJ) esclarecieron el asunto, al indicar que, si la empresa realizaba actividades comerciales, podía realizarse este tipo de procedimientos. Condiciones que, a la fecha, están más que zanjadas y cada vez son ratificadas por las leyes posteriores.

Respecto a la publicidad de los arbitrajes, hubo otro choque entre la que se predica de los asuntos de entidades estatales y públicas. Como se sabe, por regla general, los asuntos estatales son públicos -salvo reserva-, cosa que llevaba a discutir si los juicios arbitrales podían serlo también. La discusión fue superada acudiendo a fuentes internacionales, especialmente a la directiva de la unión europea No. 2004/18 del 31 de marzo de 2014, en la que se permitió dicha publicidad siempre y cuando no invadiera los ámbitos del secreto industrial y profesional. Conceptos que fueron acogidos por el ordenamiento brasilero ${ }^{19}$.

La anulación de los laudos arbitrales tenía conflictos con el término para su interposición. Ello en razón a que los laudos sobre asuntos parciales representaban problemas, en cuando a la interposición, dentro de los 90 días siguientes a su expedición o sobre el término para el laudo final. La regla general indicaba que ello sería, para ambos casos, los noventa días independientes de cada laudo. Igualmente, frente a la prórroga dentro del proceso de arbitraje, si bien no se contemplaba una obligatoria, siempre se respetó la decisión de las partes en acordar este punto. Similar postura ocurre con el nombramiento de árbitros, pues, por regla general, se permite el nombramiento por parte de los convocados al

18 Supremo Tribunal de Justiça do Brasil, ministra Nancy Andrighi. RE No 1.169.841 - RJ (2009/0239399-0). 06 de noviembre de 2012.

19 Lemes, S. M. Anotações sobre a nova Lei de arbitragem. p. 40. 
RIVERA R, Edison Leandro. Descripción legislativa preliminar del arbitraje nacional e internacional en Brasil y Colombia. Revista Eletrônica Direito e Política, Programa de Pós-Graduação Stricto Sensu em Ciência Jurídica da UNIVALI, Itajaí, v.13, n.1, $1^{0}$ quadrimestre de 2018. Disponível em: www.univali.br/direitoepolitica - ISSN 1980-7791

proceso, aunque la institución -generalmente cámara especializada- tiene autonomía para supervisar su trabajo. La voluntad también se respeta frente al derecho societario, en donde se dispone la facultad de permitir a las sociedades adoptar convenciones arbitrales inclusive desde los estatutos, eso sí, siempre y cuando las decisiones emerjan desde la misma asamblea general.

Recientemente, en Brasil se expidió la Ley 13.129 del 26 de mayo de 2015, que modificó la LA. En dicha ley, más que representar cambios significativos al régimen aplicable a la fecha, lo que se buscó fue dar armonía a los conceptos anteriormente expuestos. Así, se ratificó lo relativo a las relaciones de consumo y contratos de adhesión; se continuó con las facultades inherentes a las sociedades de economía mixta en arbitraje. La norma también ratificó las condiciones de publicidad y reserva de los asuntos en que actúe una entidad pública. A ello se le suman las disposiciones del artículo 22 y sus literales $A, B$ y $C$, frente al término para interponer la acción de anulación de laudos parciales y finales, aunado a los deberes de colaboración en medidas cautelares en procesos arbitrales, tal como también lo dispone el nuevo código de procedimiento civil. La ratificación también se extiende lo relativo al derecho societario antes mencionado, ahora disponiendo la validez de decisiones que adopten convenciones arbitrales, siempre y cuando sean tomadas por la mitad más uno de los accionistas con derecho a voto ${ }^{20}$.

En Colombia, los antecedentes del arbitraje se remontan a la misma colonia ${ }^{21}$, pasando por la antigua ley 105 de 1890, los códigos procesales de 1923 y 1931, el derogado código de procedimiento civil de 1970, en armonía con las disposiciones del código de comercio y, particularmente, la constitución política de 1991 a partir del artículo 116, tal como se refirió al principio de esta presentación. La posibilidad de que particulares, temporalmente revestidos de jurisdicción, administren justicia fue una puerta abierta a los mecanismos alternativos de solución de conflictos. Pese a ello, el decreto 1818 de 1998, fruto de la autorización legal del artículo 166 de la Ley 446 de 1998, no precisamente dio tanta apertura

\footnotetext{
20 Lemes, S. M. Anotações sobre a nova Lei de arbitragem. p. 43.

${ }^{21}$ Benitti Salgar, J. El arbitraje en el derecho colombiano (segunda ed.). Bogotá D.C.: Temis. 2001. p. 2
} 
RIVERA R, Edison Leandro. Descripción legislativa preliminar del arbitraje nacional e internacional en Brasil y Colombia. Revista Eletrônica Direito e Política, Programa de Pós-Graduação Stricto Sensu em Ciência Jurídica da UNIVALI, Itajaí, v.13, n.1, $1^{\circ}$ quadrimestre de 2018. Disponível em: www.univali.br/direitoepolitica - ISSN 1980-7791

al arbitraje, como sistema autónomo y marcadamente diferenciado del judicial ${ }^{22}$. Problemas que, solamente luego de más de diez (10) años, trataron de ser solucionados con la Ley 1563 de 2012, la cual se denomina como el "Estatuto de Arbitraje Nacional e Internacional" (EANI).

El artículo 1 del EANI, define el arbitraje en los siguientes términos:

ARTÍCULO 10. DEFINICIÓN, MODALIDADES Y PRINCIPIOS. EI arbitraje es un mecanismo alternativo de solución de conflictos mediante el cual las partes defieren a árbitros la solución de una controversia relativa a asuntos de libre disposición o aquellos que la ley autorice.

El artículo en mención estipula también los principios del arbitraje a saber: "imparcialidad, idoneidad, celeridad, igualdad, oralidad, publicidad y contradicción". Como se observa, dichos principios hacen referencia a sus pares procesales, más que a los principios del arbitraje como tal. Sin embargo, el artículo 6 de la norma en mención sí evoca lo que sería un verdadero principio del arbitraje, el denominado "autonomía de la cláusula compromisoria". De ahí que la nulidad del contrato primigenio no le afectaría a la cláusula, guardando armonía con el principio universal, que también es tomado en Brasil.

Frente al principio de "Kompetenz-Kompetenz", el ordenamiento jurídico colombiano no lo contempla expresamente. Sin embargo, los artículos 29 y 30 del EANI establecen la facultad del árbitro de, en desarrollo de la primera audiencia de trámite, decidir sobre su propia competencia. Situación que permite reafirmar la existencia tácita de éste. Ello sin hacer mención a múltiples sentencias de la corte constitucional, en las cuales ratificó dicho principio, tales como la SU-174 de 2007 y la T-288 de 2013, en vigencia del decreto 1818 de 1998 y recientemente en la Sentencia C-765/13, en donde se indicó lo siguiente:

"En la regulación actual, es decir la ley 1563 de 2012, es el artículo 29 el que consagra que el tribunal de arbitramento es la autoridad que determina si es competente para resolver el asunto objeto de controversia. Al respecto la disposición

\footnotetext{
22 Rodríguez Mejía, M. Una aproximación al régimen del arbitraje nacional del nuevo estatuto del arbitraje en Colombia, Ley 1563 de 2012. revista de derecho privado(23), 379-417. Bogotá D.C. Julio-diciembre de 2012. p. 382.
} 
RIVERA R, Edison Leandro. Descripción legislativa preliminar del arbitraje nacional e internacional en Brasil y Colombia. Revista Eletrônica Direito e Política, Programa de Pós-Graduação Stricto Sensu em Ciência Jurídica da UNIVALI, Itajaí, v.13, n.1, $1^{0}$ quadrimestre de 2018. Disponível em: www.univali.br/direitoepolitica - ISSN 1980-7791

mencionada prevé "el tribunal de arbitraje es competente para resolver sobre su propia competencia y su decisión prevalece sobre cualquier otra proferida en sentido contrario por un juez ordinario o contencioso administrativo". Decisión que, como el mismo artículo dispone de forma expresa, prevalece sobre la de otra autoridad judicial. "23

Frente a los tipos de arbitraje, el Decreto 1818 de 1998 contemplaba tres: el legal, el institucional y el ad-hoc, mientras que, actualmente, el EANI solamente contempla los dos últimos. En el arbitraje ad-hoc, son los árbitros quienes emiten sus propias normas de procedimiento, mientras que, en el institucional, las reglas son impuestas por el centro de arbitraje. El arbitraje legal era la regla general de remisión y todo arbitraje que no tuviera reglas de procedimiento se tenía que regir por el mentado decreto. Hoy en día esa regla de remisión es el arbitraje institucional, obligando a las partes a someterse a las normas de procedimiento del centro de arbitraje, ante el silencio de éstas. La doctrina ya ha encontrado problemas en esta disposición, toda vez que previamente tendría que elegirse el centro de arbitraje, cosa que puede ser complicada en una relación que nace en conflictos $^{24}$.

Colombia también experimentó dificultades frente a la suspensión o no de términos para fallar, por parte de los árbitros. El Decreto 1818 guardaba silencio en este tema, llevando a que se creyera que podía hacerse, cosa que terminó en arbitrajes extensos de hasta varios años ${ }^{25}$. El artículo 11 del EANI prevé la suspensión, sin embargo, la supedita a un término máximo de 120 días en total. Ello sin hacer mención a la práctica de pruebas en el exterior, contemplada en el artículo 31, para lo que la suspensión opera oficiosamente y de manera indefinida. Rodríguez Mejía ${ }^{26}$ encuentra también problemas en las disposiciones de la Ley 80 de 1993 Estatuto general de contratación estatal-, en tanto esta norma permite ampliar el

\footnotetext{
23 Corte Constitucional Colombiana, sala plena, M.P. Alberto Rojas Ríos Sentencia C-765 del 6 de noviembre de 2013, Bogotá D.C.

24 Rodríguez Mejía, M. Una aproximación al régimen del arbitraje nacional del nuevo estatuto del arbitraje en Colombia, Ley 1563 de 2012. p. 387.

25 Bejarano Guzmán, R. Procesos declarativos, ejecutivos y arbitrales (Quinta ed.). Bogotá D.C.: Temis. 2011. p. 484.

${ }^{26}$ Rodríguez Mejía, M. Una aproximación al régimen del arbitraje nacional del nuevo estatuto del arbitraje en Colombia, Ley 1563 de 2012. p. 390.
} 
RIVERA R, Edison Leandro. Descripción legislativa preliminar del arbitraje nacional e internacional en Brasil y Colombia. Revista Eletrônica Direito e Política, Programa de Pós-Graduação Stricto Sensu em Ciência Jurídica da UNIVALI, Itajaí, v.13, n.1, $1^{0}$ quadrimestre de 2018. Disponível em: www.univali.br/direitoepolitica - ISSN 1980-7791

término del arbitramento hasta por la mitad del inicialmente acordado, cuando se trata de contratos estatales, generando más dilaciones. De ahí que, si bien la norma tiene buenas intenciones, todavía harían faltan algunas modificaciones y precisiones.

El EANI trae interesantes innovaciones en utilización de medios electrónicos y en las causales específicas del llamado recurso extraordinario de anulación, particularmente desde el procedimiento que debe tener el tribunal arbitral para el envío del recurso al competente.

En cuanto a la integración del tribunal y el procedimiento, Brasil y Colombia guardan similitudes, sin embargo, el último es un poco menos discrecional, en tanto muchas de las fases ya están contempladas en el EANI. En Brasil, la LA, modificada por la ley 13.129 de 2015, prevé un trámite sumario, el cual solamente depende de la definición inicial de un arbitraje en equidad o en derecho, según la elección de las partes. El resto de fases, reglas y procedimientos pueden ser fijados por las partes en la cláusula compromisoria, el órgano arbitral o hasta los mismos árbitros, según se lee del artículo 5 de la LA.

Ahora bien, si las partes no tienen acuerdo previo en las reglas del arbitraje, una de las partes deberá convocar a la otra por escrito, en un lugar, fecha y hora determinados, a realizar este procedimiento y suscribir un compromiso arbitral para iniciar (artículo 6 de la LA). De no llegarse a dicho acuerdo, o ante la inasistencia, el proceso se vuelve pseudo-judicial, en tanto la solicitud debe encaminarse a un juez, ahora como una demanda. El juez que conocerá el caso intentará conciliar y, de no conseguirlo, buscará la elaboración el acuerdo arbitral. Si no se consigue el compromiso arbitral, el juez puede, con sustento en la cláusula compromisoria, nombrar el o los árbitros del proceso y emitir sentencia que servirá como compromiso, pudiendo continuar con el arbitraje, en los términos que allí se dispongan.

Ello en tanto -como se dijo- existe gran discrecionalidad en cuanto a estas reglas, aunque esto no obsta para que se cumplan requisitos mínimos, tales como la identificación de las partes, de los árbitros junto con su ubicación o de las entidades que fungirán como tal, así como la materia de litigio (Artículo 10 LA). Lo anterior, 
RIVERA R, Edison Leandro. Descripción legislativa preliminar del arbitraje nacional e internacional en Brasil y Colombia. Revista Eletrônica Direito e Política, Programa de Pós-Graduação Stricto Sensu em Ciência Jurídica da UNIVALI, Itajaí, v.13, n.1, $1^{0}$ quadrimestre de 2018. Disponível em: www.univali.br/direitoepolitica - ISSN 1980-7791

más allá de previsiones adicionales que pueden ser de mucha utilidad, como las contempladas en el artículo 11 de la LA, entre las que se destacan el lugar del arbitraje, la autorización para juzgar en equidad -si así se conviene-, el plazo para la emisión de la sentencia, las leyes nacionales o corporativas aplicables, el responsable de honorarios y hasta su fijación.

Frente a la escogencia de árbitros, se debe propender por un número impar. Cada parte puede nombrar uno o varios árbitros, dependiendo del asunto e inclusive cualquier persona capaz puede ser nombrada, siempre y cuando tenga la confianza de las partes. Las diferencias entre la elección del árbitro que vuelva impar la cifra serán resueltas por la justicia, con base en el procedimiento fijado para el compromiso arbitral anteriormente expuesto.

En cuanto a los impedimentos y recusaciones de que pueden ser objeto los árbitros, el artículo 14 de la LA remite expresamente estos asuntos a las causales contempladas en el código de proceso civil (CPC), hoy ley 13.105 del 16 de marzo de 2015, particularmente el artículo 144 y ss. Causales que tienen que ver con: haber conocido el caso, servir de mandatario de alguna de las partes, ser socio de una empresa del litigio, entre otras situaciones que podrían poner en entredicho su independencia o imparcialidad. El trámite le obliga al árbitro a poner en conocimiento dichas situaciones, declarando su impedimento. De igual manera, en caso de que el árbitro no se declare impedido, las partes podrán recusarlo antes o después de su nominación, dependiendo de cuándo conocieron la causal. La sustitución del árbitro puede darse de común acuerdo o conforme al multicitado compromiso arbitral expuesto.

Los términos para la emisión del laudo es un asunto mucho más discrecional, eso sí, bajo el respeto de las reglas y principios de prueba y juzgamiento. En este procedimiento es permitida la suspensión de común acuerdo e inicialmente se contemplaba una suspensión, de acuerdo con las necesidades de los árbitros, pero ello fue derogado. El laudo tiene fuerza material de sentencia y hace tránsito a cosa juzgada, sirviendo de título para eventuales ejecuciones.

En Colombia la iniciación del arbitraje se remite a lo contemplado en el artículo 12 del EANI, que indica la necesidad de una demanda ante el centro de arbitraje 
RIVERA R, Edison Leandro. Descripción legislativa preliminar del arbitraje nacional e internacional en Brasil y Colombia. Revista Eletrônica Direito e Política, Programa de Pós-Graduação Stricto Sensu em Ciência Jurídica da UNIVALI, Itajaí, v.13, n.1, $1^{0}$ quadrimestre de 2018. Disponível em: www.univali.br/direitoepolitica - ISSN 1980-7791

designado o alguno radicado en el domicilio del demandado. Los requisitos son los mismos de cualquier demanda ante la jurisdicción ordinaria y los centros de arbitraje son estrictos en cuanto a la competencia, debiendo remitir al competente, en caso de no serlo. Ello sin hacer mención a los trámites especiales que contempla la demanda a una entidad estatal, la cual contempla hasta la notificación a la Agencia Nacional para la Defensa Jurídica del Estado, entidad de reciente creación y que, por regla general, debe conocer todo debate en el que intervengan los órganos estatales, más allá de la defensa propia que cada uno de éstos tiene.

El EANI contempla la posibilidad de acudir al arbitraje solicitando el llamado "amparo de pobreza", con lo que el demandante, de reunir los requisitos, puede evitarse el pago de los gastos del proceso y recibir la asignación de un abogado.

La designación de árbitros es similar a la de Brasil. Las partes pueden: elegir los árbitros, delegar su conformación al centro de arbitraje -en la cláusula compromisoria- o hasta un juez del circuito puede designarlos a falta de las dos opciones anteriores. Los árbitros tienen el deber de informar las circunstancias que pueden viciar su imparcialidad o las relaciones con alguna de las partes. De ahí que el régimen de impedimentos y recusaciones también sea remitido a lo contemplado en el procedimiento civil, especialmente el Código General del Proceso. Superado ello y aceptado el nombramiento, los árbitros eligen un presidente y un secretario con el cual continuarán el trámite (artículo 20 del EANI).

Frente al trámite como tal, los términos generales fueron fijados por el EANI. Así, el artículo 21 prevé un traslado de la demanda por veinte (20) días para que el demandado conteste y proponga excepciones, sumado a otro de cinco (5) días para el demandante, en el cual podrá modificar o reformar la demanda. Vencidos estos traslados, el proceso continúa con la citación a audiencia de conciliación de que trata el artículo 24, en donde inclusive puede intervenir el ministerio público órgano de defensa de derechos y control disciplinario en Colombia-. En la misma audiencia, de no lograrse acuerdo, se pasará a la fijación de gastos y honorarios, según los parámetros de la ley (Artículo 26), salvo que, previo a la designación de los árbitros, ya se hubieren fijado. Los honorarios deben pagarse dentro de los 
RIVERA R, Edison Leandro. Descripción legislativa preliminar del arbitraje nacional e internacional en Brasil y Colombia. Revista Eletrônica Direito e Política, Programa de Pós-Graduação Stricto Sensu em Ciência Jurídica da UNIVALI, Itajaí, v.13, n.1, $1^{0}$ quadrimestre de 2018. Disponível em: www.univali.br/direitoepolitica - ISSN 1980-7791

diez días siguientes, so pena de terminarse el arbitramento y los efectos del pacto arbitral (compromiso o cláusula compromisoria).

El proceso continúa con la realización de la primera audiencia de trámite, contemplada en el artículo 30, en la cual se aplica el principio "KompetenzKompetenz", pudiendo el tribunal arbitral resolver sobre su propia competencia, así como la solicitud de pruebas de las partes o las que, de oficio, considere pertinente, dando inicio al periodo probatorio. En dicho periodo, pueden practicarse las audiencias de pruebas que se consideren necesarias, respetándose las reglas y principios de la prueba judicial, así como la asignación de los gastos y honorarios que éstas generen, en caso de requerir informes periciales. Finalmente, se citará a las partes a rendir sus alegatos de conclusión, para luego fijar una fecha en la que se expedirá el laudo.

EI EANI prevé múltiples herramientas interesantes para la conservación y registro del laudo, la utilización de medios electrónicos, el procedimiento para el reembolso de honorarios, así como la integración del contradictorio y citación de terceros, en caso de ser necesario. Sin embargo, a grandes rasgos, el procedimiento se ha descrito y se ha planteado la diferencia con el ordenamiento brasilero.

Ahora bien, ambos ordenamientos tienen similitudes frente a las medidas o tutelas cautelares y recursos o demandas. En ambos ordenamientos se pueden pedir medidas a los jueces, previo a la interposición de la demanda. Igualmente, el árbitro está facultado para decretar las medidas o tutelas a que haya lugar. En Colombia inclusive el árbitro puede decretar las medidas cautelares innominadas que sean necesarias para la efectividad de un derecho o de una prueba. La facultad es tan amplia en Colombia que la norma permite decretar este tipo de medidas, inclusive a múltiples órganos que no gozan de la condición de jueces o árbitros.

Ambas legislaciones contemplan la utilización de recursos y demandas frente a las decisiones arbitrales. La más simple es la aclaración, que opera en ambos casos durante la ejecutoria del laudo, pudiendo pedirse la corrección de errores aritméticos o la explicación de partes oscuras de la decisión. Brasil tiene un mecanismo directo contra el laudo y es una demanda de nulidad ante el órgano competente, dentro de los noventa (90) días siguientes a su notificación. la justicia 
RIVERA R, Edison Leandro. Descripción legislativa preliminar del arbitraje nacional e internacional en Brasil y Colombia. Revista Eletrônica Direito e Política, Programa de Pós-Graduação Stricto Sensu em Ciência Jurídica da UNIVALI, Itajaí, v.13, n.1, $1^{0}$ quadrimestre de 2018. Disponível em: www.univali.br/direitoepolitica - ISSN 1980-7791

ordinaria es la competente para desatar dicha demanda, de acuerdo con el CPC. Las causales de nulidad son taxativas y están enlistadas en el artículo 32 de la LA y los efectos de una sentencia de nulidad contemplan la orden al tribunal de emitir una nueva sentencia.

En Colombia, dicha demanda es un recurso y debe interponerse y sustentarse ante el tribunal arbitral, dentro de los treinta (30) días siguientes a su notificación. Del recurso se corre traslado por quince (15) días a la contraparte y luego de cinco (5) días se envía a la sala civil del tribunal superior del distrito judicial al que estén vinculados, quien desatará el recurso. Con base en el artículo 42 del EANI, la sentencia que ponga fin al recurso no debe tramitarse en más de tres (3) meses, pero la congestión judicial puede hacer que ello no se cumpla. Los efectos de la anulación son diversos: puede corregirse y adicionarse la decisión, si las causales no afectan son la validez de la decisión; puede anularse y enviarse al juez competente, si la causal afecta la competencia del tribunal de arbitramento; o puede declararse nulo, pero conservar la validez de las pruebas, pudiendo integrarse nuevamente el tribunal de arbitramento (Artículo 43).

Otro recurso con el que se cuenta en Colombia es el de revisión. Dicho recurso se puede interponer contra el laudo y hasta contra la sentencia de anulación. El recurso solamente indaga sobre aspectos formales y se da en sentencias de única instancia, siendo competencia de la sala civil de la Corte Suprema de Justicia.

\section{EL ARBITRAJE INTERNACIONAL: RETOS Y AVANCES EN BRASIL Y COLOMBIA}

A partir de lo anterior, se evidencian dos situaciones que marcarán la pauta del arbitraje, pero esta vez internacional: La importancia de la convención de Nueva York y la diferencia marcada con el arbitraje local. En Brasil la LA no contempla mayores regulaciones frente al arbitraje internacional, más allá del procedimiento para reconocimiento y ejecución de laudos extranjeros, lo que permitía una aplicación más prolija de la Convención de Nueva York y las reglas de la UNICITRAL, en clara prevalencia del derecho convencional ${ }^{27}$. Por su parte,

\footnotetext{
27 Tiburcio, C A arbitragem internaciona: definição e questões polêmicas. Revista de Arbitragem e mediação, XI(40), 253-285. Brasilia. enero de 2014. p. 269-272.
} 
RIVERA R, Edison Leandro. Descripción legislativa preliminar del arbitraje nacional e internacional en Brasil y Colombia. Revista Eletrônica Direito e Política, Programa de Pós-Graduação Stricto Sensu em Ciência Jurídica da UNIVALI, Itajaí, v.13, n.1, $1^{\circ}$ quadrimestre de 2018. Disponível em: www.univali.br/direitoepolitica - ISSN 1980-7791

Colombia, si bien inicialmente la Ley 315 de 1996 trataba de regular el tema, muchas veces debía remitirse el asunto al procedimiento del Decreto 1818 de 1998, para llenar los vacíos de la regulación referente al arbitraje internacional, así como a la Convención de Nueva York y la Convención Interamericana sobre el Arbitraje Comercial (CIAC) de 1975 o Convención de Panamá28. Hoy en día EANI trae un procedimiento completo sobre el cual aplicar este arbitraje, con importantes actualizaciones a la norma internacional, eso sí, garantizando la prevalencia de los principios del arbitraje internacional.

Como se evidencia, ambos sistemas habían sido muy laxos en la aplicación de procedimientos, dándose relevancia a la autonomía de las partes. El artículo 2 de la Ley 315 llegaba a elevar esta autonomía no solamente a aspectos procedimentales, sino sustanciales. De ahí que, en Colombia, fácilmente se podía hablar de un régimen dualista: de autonomía para el arbitraje internacional y ritualista para el nacional ${ }^{29}$. En Brasil esto no parecía suceder, el régimen es igual para ambos y las discusiones pasan más por la homologación, algunas medidas cautelares y el orden público ${ }^{30}$.

Lo anterior no quiere decir que Brasil se escape a las discusiones entre la aplicación de leyes nacionales o lex fori, extranjeras o las transnacionales. Uno de los grandes principios del arbitraje internacional es la conservación del orden público internacional, el cual comprende aspectos sustanciales y procesales, así como principios de justicia y moralidad. De tal manera que los arbitrajes en Brasil deben respetar dicho orden público, so pena de no ser válidos en el extranjero e inclusive ser anulados en el ámbito local. La aplicación de este orden público internacional se puede dar independiente de los derechos nacionales, especialmente cuando se

\footnotetext{
28 Strong, S. El arbitraje internacional en Colombia desde una perspectiva estadounidense. Revista internacional de arbitraje(15), 145-239. Julio-diciembre de 2011. Disponible en http://legal.legis.com.co/document? obra=rarbitraje\&document=rarbitraje_c0de71112cfe0038e0430a0101510038. Último acceso el 15 de diciembre de 2017. p. 160

29 Rodríguez Mejía, M. Una aproximación al régimen del arbitraje nacional del nuevo estatuto del arbitraje en Colombia, Ley 1563 de 2012. p. 383

30 Tiburcio, C A arbitragem internaciona: definição e questões polêmicas. p. 272-277
} 
RIVERA R, Edison Leandro. Descripción legislativa preliminar del arbitraje nacional e internacional en Brasil y Colombia. Revista Eletrônica Direito e Política, Programa de Pós-Graduação Stricto Sensu em Ciência Jurídica da UNIVALI, Itajaí, v.13, n.1, $1^{0}$ quadrimestre de 2018. Disponível em: www.univali.br/direitoepolitica - ISSN 1980-7791

discuten asuntos relativos a moralidad contractual e intereses fundamentales del comercio ${ }^{31}$.

Ahora bien, existes tres circunstancias que pueden complicar un poco más el asunto: cuando las partes no deciden qué norma aplicar; cuando deciden normas de un ordenamiento nacional y parte de normas transnacionales de lex mercatoria y, finalmente; cuando eligen solamente normas de un ordenamiento nacional. En el primero de los casos, el árbitro tiene cierta libertad para optar por las normas que cuiden el orden público internacional, sin que ello se convierta en activismo. El segundo de los casos genera un problema, ya que se está ante la autonomía de las partes y el orden público; situación en la que la lex mercatoria debe servir como complemento del ordenamiento local. El tercer caso es todavía más dificultoso, ya que impone la aplicación de la ley local, sin embargo, en Brasil, conforme a la jurisprudencia y al artículo 4 de la ley de introducción a las normas del derecho brasilero, si la ley omite aspectos, bien podría hacerse uso de la lex mercatoria o de la norma transnacional que sirva para el caso ${ }^{32}$.

Frente a la homologación de laudos existen dos épocas relevantes en Brasil: antes y después de la LA. La primera fue un desarrollo prácticamente jurisprudencial, pues la norma regulatoria no diferenciaba entre arbitraje internacional y nacional. Los debates en esta época se redujeron a determinar la competencia para conocer la legalidad del laudo, ya fuera de acuerdo con el objeto o la sede, asumiéndose una inclinación hacia este último. Con la expedición de la LA, sus artículos 34 y 31 resolvieron el asunto, estimando que si el laudo era emitido fuera de Brasil debía ser homologado y si por el contrario era expedido al interior del país, no requería del mecanismo. Igualmente, es importante destacar que, en esta determinación, no se hizo diferencia alguna entre arbitraje extranjero y arbitraje internacional ${ }^{33}$.

31 Moreno Rodríguez, J. A. Direito aplicável e arbitragem internacional. (F. Glitz, Trad.) Curitiba: Juruá Editora. 2015. p. 441-442.

32 Monteiro Nitschke, G. C. Ativismo arbitral e lex mercatoria. mediação, XII(44), 89-122. Enero-marzo de 2015. p. 120-123

33 Tiburcio, C A arbitragem internaciona: definição e questões polêmicas. p. 259-262 
RIVERA R, Edison Leandro. Descripción legislativa preliminar del arbitraje nacional e internacional en Brasil y Colombia. Revista Eletrônica Direito e Política, Programa de Pós-Graduação Stricto Sensu em Ciência Jurídica da UNIVALI, Itajaí, v.13, n.1, $1^{\circ}$ quadrimestre de 2018. Disponível em: www.univali.br/direitoepolitica - ISSN 1980-7791

La homologación del laudo arbitral pasó de ser doble, conforme de las disposiciones del Decreto 6982 de 1878; para ser simple, de acuerdo con las disposiciones del artículo 18, 31, 25, 28 y 39 de la Ley 9307 de 1996. Ello precedido de un difícil cambio en el Supremo Tribunal Federal en el que inclusive se debatió un incidente de inconstitucionalidad, permitiéndose, a la fecha, consolidar dos tipos de homologación de laudos a saber: simple para laudos que tengan fuerza judicial en el país de origen y doble para los que no lo tengan debiendo homologarse en las dos sedes ${ }^{34}$.

En Colombia, la sección tercera del EANI, a partir del artículo 62, contempla un completo y moderno procedimiento de arbitraje internacional. En este procedimiento se les da abierta aplicación a los principios de autonomía de la cláusula, autonomía de las partes y la convencionalidad. Con base en el artículo 101 del EANI, son las partes quienes eligen las leyes aplicables y, en todo caso, de no manifestar su voluntad, el árbitro podrá aplicar la correspondiente, con base en las costumbres mercantiles y las estipulaciones contractuales.

La norma empieza por definir el arbitraje internacional, con base en tres circunstancias a saber:

"a) Las partes en un acuerdo de arbitraje tengan, al momento de la celebración de ese acuerdo, sus domicilios en Estados diferentes; 0

b) El lugar del cumplimiento de una parte sustancial de las obligaciones o el lugar con el cual el objeto del litigio tenga una relación más estrecha, está situado fuera del Estado en el cual las partes tienen sus domicilios; o

c) La controversia sometida a decisión arbitral afecte los intereses del comercio internacional." (Artículo 62 EANI)

Esta definición guarda armonía con las tendencias internacionales, incluyendo la brasilera. A ello se le suma que, por expresa disposición del artículo 64, el trabajo interpretativo en este tipo de procesos se base en los principios generales del arbitraje internacional, así como a lo consignado por las partes previamente.

\footnotetext{
34 Tiburcio, C A arbitragem internaciona: definição e questões polêmicas. P. 272
} 
RIVERA R, Edison Leandro. Descripción legislativa preliminar del arbitraje nacional e internacional en Brasil y Colombia. Revista Eletrônica Direito e Política, Programa de Pós-Graduação Stricto Sensu em Ciência Jurídica da UNIVALI, Itajaí, v.13, n.1, $1^{0}$ quadrimestre de 2018. Disponível em: www.univali.br/direitoepolitica - ISSN 1980-7791

La intervención judicial en este proceso es mínima y radica en el simple nombramiento de árbitros y su recusación, cuando no se hayan puesto de acuerdo las partes o el tribunal no pudiere decidirlo, acorde a las previsiones del artículo 73 y 76. Igualmente, la intervención se reduce solamente al recurso de anulación del artículo 107, en tanto ya no se prevé el recurso de revisión que sí se ha dispuesto para el arbitraje nacional.

En cuanto a las medidas cautelares, el EANI permite la práctica de las que el tribunal arbitral:

"a) Mantenga o restablezca el status quo en espera de que se dirima la controversia;

b) Adopte medidas para impedir algún daño presente o inminente, o el entorpecimiento del procedimiento arbitral, o que se abstenga de realizar actos que probablemente ocasionarían dicho daño o entorpecimiento al procedimiento arbitral;

c) Proporcione algún medio para preservar bienes cuya conservación permita ejecutar el o los laudos; o

d) Preserve elementos de prueba que pudieran ser pertinentes y relevantes para resolver la controversia." (artículo 80 EANI)

Las medidas pueden ser previas o durante el proceso e inclusive no requieren notificación de parte, aunque hay que argumentar la necesidad y la idoneidad de la medida u orden. Sin embargo, las medidas también pueden ser denegadas si: 1. vulnera el ordenamiento elegido por las partes, 2. reza sobre controversias no previstas en el acuerdo arbitral, 3. el asunto no sea susceptible de arbitraje, de acuerdo con el ordenamiento colombiano o 4. la orden menoscabe el orden público internacional. Las medidas también pueden ser ordenadas por la autoridad judicial, pero ello se someterá a las reglas generales del proceso colombiano.

El EANI otorga a las partes autonomía para decidir sobre la sede del arbitraje (Artículo 93), idioma del proceso (artículo 95) y la práctica de pruebas. El proceso inicia con una demanda donde exponga los hechos, puntos controvertidos y objeto de la petición, allegando las pruebas que se anexan y la solicitud de las que se practicarán. Los plazos para interponer la demanda y dar contestación se fijarán 
RIVERA R, Edison Leandro. Descripción legislativa preliminar del arbitraje nacional e internacional en Brasil y Colombia. Revista Eletrônica Direito e Política, Programa de Pós-Graduação Stricto Sensu em Ciência Jurídica da UNIVALI, Itajaí, v.13, n.1, $1^{0}$ quadrimestre de 2018. Disponível em: www.univali.br/direitoepolitica - ISSN 1980-7791

por las partes desde la conformación del tribunal. Éstos pueden ser adicionados de común acuerdo, lo cual no implica que no deban ser cumplidos, así como los requisitos que inicialmente se pacte para su presentación.

Las actuaciones podrán llevarse por escrito o en audiencias, según lo prevean las partes. Las pruebas tienen las mismas características, salvo las periciales, donde las partes deberán prestar su colaboración a los expertos y podrán escuchar sus presentaciones en audiencia.

De igual manera, si bien, por regla general, las decisiones del tribunal se tomarán por mayorías, las partes podrán pactar otras circunstancias especiales. Igual ocurre con el laudo arbitral, el cual podrá ser motivado o no, salvo si alguna de las partes tiene su domicilio en Colombia. El laudo constará por escrito y se entregará en copias a cada una de las partes, siendo susceptible de corrección o aclaración, en caso de que haya dudas o errores en éste. La libertad de las partes es tan amplia que, en cualquier momento, podrán terminar la actuación por transacción, conciliación o mediación, para lo que se emitirá laudo con las condiciones allí acordadas. Ello sin hacer mención a las facultades del artículo 105, el cual permite terminar el proceso si se retira la demanda, las partes lo acuerden o sea innecesario o imposible, amén de la expiración del plazo.

Frente a la homologación de laudos, que en Colombia se le denomina reconocimiento, el EANI establece un procedimiento sencillo y, a priori, rápido. Todos los laudos expedidos en el extranjero pueden ser reconocidos en Colombia, por parte de la Sala de Casación Civil de la Corte Suprema de Justicia.

Colombia, al igual que Brasil, tuvo la eterna discusión de si el procedimiento aplicable a la homologación de laudos era el del execuátur o si correspondía a un trámite especial. Durante veintiún (21) años se aplicó execuátur, con base en el extinto Decreto 1400 de 1970 o Código de Procedimiento Civil. Sin embargo, desde el año 1991 la jurisprudencia resolvió el asunto, dejando claro que se trataba de 
RIVERA R, Edison Leandro. Descripción legislativa preliminar del arbitraje nacional e internacional en Brasil y Colombia. Revista Eletrônica Direito e Política, Programa de Pós-Graduação Stricto Sensu em Ciência Jurídica da UNIVALI, Itajaí, v.13, n.1, $1^{\circ}$ quadrimestre de 2018. Disponível em: www.univali.br/direitoepolitica - ISSN 1980-7791

un trámite especial ${ }^{35}$. El EANI elucida completamente el tema, al disponer del procedimiento contemplado en los artículos 111 y siguientes.

A pesar de lo anterior y contrario al caso brasilero, Colombia no tiene muy buena fama para realizar estos arbitrajes ${ }^{36}$. El cuarenta porciento (40\%) de los arbitrajes nacionales se llevan en el centro de arbitraje de la cámara de comercio de Bogotá D.C. y ni siquiera ésta es una entidad buscada frecuentemente para ser sede internacional, aparentemente por cierta fama de llevar controversias multilaterales, integrando terceros sin razón alguna ${ }^{37}$, generalmente como consecuencia del sistema dualista que lleva a confusiones.

Cosa distinta ocurre en Brasil desde la expedición de la LA, donde, además de haber un aumento en la homologación de laudos, ha sido predilecto para ser sede de arbitrajes internacionales. No extraña que, en 2012, fuera el séptimo (70) país en el mundo más elegido para ser sede de estos arbitrajes ${ }^{38}$. Además de las evidentes condiciones comerciales superiores del gigante de Sudamérica, la estrategia de Brasil se basa en hacer un arbitraje pragmático y similar al inglés, buscando una eficiencia y exactitud de las decisiones ${ }^{39}$, lo cual implica la utilización de árbitros especializados. Situación que le ha dado réditos y le seguirá dando, sirviendo de ejemplo para países como Colombia que, a pesar de su interesante normatividad, requiere también la adopción de prácticas más eficaces y una renovación en sus árbitros.

35 Corte Suprema de Justicia de Colombia, Sala de Casación Civil, M.P. José Fernando Ramírez Gómez, Merck c. vs. Tecnoquímicas sentencia del 1 de marzo de 1999.

36 Lozada Pimiento, N. Diferencias entre exequátur y reconocimiento de laudos arbitrales internacionales. Ámbito jurídico. 05 de febrero de 2014. Bogotá D.C. Disponible en https://www.ambitojuridico.com/noticias/educacion-y-cultura/diferencias-entre-exequatur-yreconocimiento-de-laudos-arbitrales último acceso el 04 de mayo de 2018.

37 Strong, S. El arbitraje internacional en Colombia desde una perspectiva estadounidense. p. 200, 201 y 2002.

38 Wald, A. A importância da arbitragem internacional em 2013. Revista de Arbitragem e mediação, 101-110. Brasilia. Julio-septiembre de 2013. p. 102

39 Wald, A. A importância da arbitragem internacional em 2013. p. 109. 
RIVERA R, Edison Leandro. Descripción legislativa preliminar del arbitraje nacional e internacional en Brasil y Colombia. Revista Eletrônica Direito e Política, Programa de Pós-Graduação Stricto Sensu em Ciência Jurídica da UNIVALI, Itajaí, v.13, n.1, $1^{\circ}$ quadrimestre de 2018. Disponível em: www.univali.br/direitoepolitica - ISSN 1980-7791

\section{CONSIDERACIONES FINALES}

Los mecanismos alternativos de solución de conflictos están arraigados en casi todos los ordenamientos jurídicos de tradición continental europea. La historia de los países latinoamericanos tiene vestigios de más de cincuenta años en la estipulación normativa de estos mecanismos. Pese a ello, solamente en la última década del siglo XX y primeras del siglo XXI se ha podido evidenciar un mayor auge de éstos.

El arbitraje es uno de los mecanismos por excelencia e involucra la administración de justicia, por parte de particulares. Hecho que pudo ser atractivo inicialmente por la descongestión judicial que representaba, pero que en verdad se ha convertido en una herramienta útil y práctica.

Brasil y Colombia comparten similitudes en sus formas de regular el arbitraje internacional. Ambos ratificaron la convención de Nueva York y manejan una prelación del ordenamiento internacional y las normas del orden público internacional, sobre el ordenamiento local, en tratándose de arbitraje internacional. Pese a ello, Colombia adoptó desde hace más de veinte (20) años un sistema dualista, en el que se diferencia tajantemente la aplicación del principio de autonomía de las partes, si se trata de arbitraje nacional o internacional.

Así, en Colombia no es extraño que hasta se haya regulado, de forma eficiente, el arbitraje internacional, con múltiples referencias a los movimientos mundiales más actuales del tema. A contrario sensu, parece que el arbitraje nacional, aun cuando el EANI parece generar un gran avance, puede seguir siendo un obstáculo a la aplicación de principios internacionales de arbitraje y, particularmente, la voluntad de las partes.

Brasil lleva más de veinte años con importantes avances en la aplicación de su arbitraje. Aparentemente no existe un dualismo, ya que la LA es igual tanto para los arbitrajes nacionales como para los internacionales. No obstante, previo a dicha norma, el país pasó por serios problemas en cuanto a la definición de normas aplicables, homologación de laudos y práctica de medidas cautelares. Situación que llevó a cierta ola revolucionaria, la cual no necesariamente ha sido 
RIVERA R, Edison Leandro. Descripción legislativa preliminar del arbitraje nacional e internacional en Brasil y Colombia. Revista Eletrônica Direito e Política, Programa de Pós-Graduação Stricto Sensu em Ciência Jurídica da UNIVALI, Itajaí, v.13, n.1, $1^{\circ}$ quadrimestre de 2018. Disponível em: www.univali.br/direitoepolitica - ISSN 1980-7791

completamente buena, en tanto se ha apreciado en los últimos años algunos intentos de activismo arbitral, que puede interferir en el buen trabajo hasta ahora desempeñado.

A diferencia de Brasil, Colombia suele tener más organizado su sistema legal. La norma que regula ambos arbitrajes es reciente y es muy completa. Pese a ello, esto puede ser un arma de doble filo, ya que, por ejemplo, Brasil ha permitido mucho más la aplicación de principios y normas internacionales a estos procesos, a partir de la falta de norma. Colombia pudo haberle pasado lo mismo, pero parecería que la tradición jurídica es un poco más conservadora, llevando a adoptar maniobras restrictivas de la actuación del árbitro.

Finalmente, las reformas legales adoptadas recientemente por Colombia pueden llevar a un auge en su producción arbitral. Eso sí, se requerirá también de cambios sustanciales en la forma en que los árbitros dirigen los procesos y adoptan decisiones. Para ello, el caso de Brasil puede ser un interesante ejemplo que seguir, especialmente por su abundante crecimiento en el tema y su condición de referente mundial.

\section{REFERENCIA DE LAS FUENTES CITADAS}

Álvarez, G. S. (05 de agosto de 2017). Mapa regional de resolución alernativa de disputas. Recuperado el 23 de noviembre de 2017, de http://www.maparegional.gob.ar/accesoJusticia/documents/verDocumento.html? idDocumento $=1$

Bejarano Guzmán, R. (2011). Procesos declarativos, ejecutivos y arbitrales (Quinta ed.). Bogotá D.C.: Temis.

Benitti Salgar, J. (2001). El arbitraje en el derecho colombiano (segunda ed.). Bogotá D.C.: Temis.

Borges Motta, F. J., \& Tomaz de Olivera, R. (2016). Livro II Da função jurisdiccional - Título I Da jurisdição e da ação. En L. L. Streck, D. Nunes, \& L. Carneiro da cunha, Comentários ao Código de proceso civil (págs. 64-87). São Paulo: Editoria Saraiva.

Cappeletti, M., \& Garth, B. (1996). El acceso a la justicia: la tendencia en el movimiento mundial para hacer efectivos los Derechos. México D.F.: Fondo de Cultura Económica. 
RIVERA R, Edison Leandro. Descripción legislativa preliminar del arbitraje nacional e internacional en Brasil y Colombia. Revista Eletrônica Direito e Política, Programa de Pós-Graduação Stricto Sensu em Ciência Jurídica da UNIVALI, Itajaí, v.13, n.1, $1^{\circ}$ quadrimestre de 2018. Disponível em: www.univali.br/direitoepolitica - ISSN 1980-7791

Caso Merck c. Tecnoquímicas, Sala de Casación Civil, M.P. José Fernando Ramírez Gómez ( Corte Suprema de Justicia 1 de marzo de 1999).

De Souza Tavares, V. (febrero de 2014). Arbitragem no Brasil. Âmbito Jurídico, XVII(121). Recuperado el 26 de enero de 2018, de http://www.ambitojuridico.com.br/site/?n_link=revista_artigos_leitura\&artigo_id=14424

Fernandes Marques, A., Teixeira, L. X., \& Amaral, N. (2013). Mecanismos alternativos de solução de conflitos: conciliação, mediação e arbitragem. Ponto de Vista Jurídico, 32-48.

Folberg, J., \& Taylor, A. (s.f.).

Lemes, S. F. (1999). Aspectos fundamentais da Lei de Arbitragem. Rio de Janeiro: Forense.

Lemes, S. M. (Octubre - diciembre de 2015). Anotações sobre a nova Lei de arbitragem. Revista de arbitragem e mediação, XVII, 37-44.

Lew, J., Mistelis, L., \& Kröll, S. (2003). The Hague: Comparative International Commercial Arbitration. Alphen aan den Rijn, Holanda: Kluwer Law International.

Lopes, J. R. (2006). Direitos sociais: teoría e prática. São Paulo: Método.

Lozada Pimiento, N. (05 de febrero de 2014). Diferencias entre exequátur y reconocimiento de laudos arbitrales internacionales. ámbito jurídico.

Mitsuo Miura, A., \& Nasser Vidal, R. C. (Diciembre de 2016). A relativização do principio Kómpetenz - Kómpetenz pelo ST]: Um breve comentário ao julgamento do recurso especial 1.602.076/SP. Revista Jurídica da Escola Superior de Advocacia da OAB-PR, año 1(2), 316-339. Recuperado el 31 de enero de 2018, de http://revistajuridica.esa.oabpr.org.br/wp-content/uploads/2016/12/2-0revista-juridica.pdf

Monteiro Nitschke, G. C. (Enero-marzo de 2015). Ativismo arbitral e lex mercatoria. Revista de arbitragem e mediação, $X I I(44)$, 89-122.

Moreno Rodríguez, J. A. (2015). Direito aplicável e arbitragem internacional. (F. Glitz, Trad.) Curitiba: Juruá Editora.

Palandri, E. (2015). Manual de formación básica en mediación. Córdoba, Argentina: Ediciones Alveroni.

RE No 1.169.841 - RJ (2009/0239399-0), Recurso especial, ministra Nancy Andrighi (Supremo Tribunal de Justiça do Brasil 06 de noviembre de 2012).

Rodríguez Mejía, M. (Julio-diciembre de 2012). Una aproximación al régimen del arbitraje nacional del nuevo estatuto del arbitraje en Colombia, Ley 1563 de 2012. revista de derecho privado(23), 379-417. 
RIVERA R, Edison Leandro. Descripción legislativa preliminar del arbitraje nacional e internacional en Brasil y Colombia. Revista Eletrônica Direito e Política, Programa de Pós-Graduação Stricto Sensu em Ciência Jurídica da UNIVALI, Itajaí, v.13, n.1, $1^{0}$ quadrimestre de 2018. Disponível em: www.univali.br/direitoepolitica - ISSN 1980-7791

Salcedo Flórez, Á. (2012). La autonomía de las partes en el arbitraje ad hoc frente al orden público procesal (Primera ed.). Bogotá D.C.: Universidad de Bogotá Jorge Tadeo Lozano.

Sentencia C-765/13, M.P. Alberto Rojas Ríos (Corte Constitucional Colombiana, sala plena 6 de noviembre de 2013).

Strong, S. (Julio-diciembre de 2011). El arbitraje internacional en Colombia desde una perspectiva estadounidense. Revista internacional de arbitraje (15), 145239. Recuperado el 15 de 12 de 2017, de http://legal.legis.com.co/document?obra=rarbitraje\&document=rarbitraje_c0de7 1112cfe0038e0430a0101510038

Tiburcio, C. (enero de 2014). El arbitraje internacional - Definición y cuestiones polémicas. Revista de Arbitragem e mediação, XI(40), 253-285.

TSDF No. Apelação cível no 1999.01.1.083360-3, Desembargador Vasquez Cruxên, partes Americel S/A vs Compushopping informática Itda ME e outros (Tribunal de Justiça do Distrito Federal e Territórios - 3ra Turma civil 2001 de marzo de 2001).

Wald, A. (Julio-septiembre de 2013). A importância da arbitragem internacional em 2013. Revista de Arbitragem e mediação, 101-110.

Recebido em: 06/04/2018

Aprovado em: 08/08/2018 